\title{
Camostat mesilate therapy for COVID-19
}

\author{
Yoshiharu Uno ${ }^{1}$
}

Received: 31 March 2020 / Accepted: 11 April 2020 / Published online: 29 April 2020

(c) Società Italiana di Medicina Interna (SIMI) 2020

\section{Dear Editor,}

Novel coronavirus disease (COVID-19), caused by severe acute respiratory syndrome coronavirus 2 (SARS-CoV-2), is a global threat. Antivirals and vaccines need to be developed to control the disease. This not only entails a considerable expense, it would also take some time for a newly developed drug to be tested for safety and, in the meantime, several more deaths would be inevitable. Under these exigent conditions, the administration of the already developed safe drugs should be the smartest shortcut.

TMPRSS2 is a serine protease that primes the spike protein of highly pathogenic human coronaviruses, such as severe acute respiratory syndrome-related coronavirus (SARS-CoV) and Middle East respiratory syndromerelated coronavirus (MERS-CoV), and facilitates its entry into the host cell. Camostat mesilate (CM), an inhibitor of TMPRSS2, blocked the spread and pathogenesis of SARS$\mathrm{CoV}$ in a pathogenic mouse model and would be expected to show similar effect in MERS-CoV [1, 2]. Hoffmann et al. determined that the SARS-CoV-2 requires TMPRSS2 [3]. Furthermore, using a sample of SARS-CoV-2 virus isolated from a patient, they found that CM blocks the entry of the virus into the lung cells.

CM was developed in Japan as a protease inhibitor in the 1980s and because most of the studies on this compound have been published in Japanese, very little information is available outside of Japan. In Japan, CM therapy for acute symptoms of chronic pancreatitis is covered by health insurance since 1985, and it has also been used to treat postoperative reflux esophagitis since 1994; the oral doses used in these cases are 600 and $300 \mathrm{mg} /$ day, respectively. In a multi-centre, double-blind study on 189 subjects, $3 \%$ of the subjects in the group administered $900 \mathrm{mg} \mathrm{CM}$ daily for

Yoshiharu Uno

yoshiharu333@hotmail.com

1 Office Uno Column, 419-2, Yota, Onoe-cho, Kakogawa, Hyogo, Japan
8 weeks showed side effects (oedema and urticaria); however, there were no side effects over the 8 weeks period in the groups that received a daily CM dose less than $600 \mathrm{mg}$ [4]. In the recent years in Japan, the number of people taking $\mathrm{CM}$ for 1 year is estimated to be about 100,000 , where only one case of acute eosinophilic pneumonia by $\mathrm{CM}$ was reported in 2016 [5]. This case was of a 75-year-old man, where pulmonary infiltration with peripheral blood eosinophilia appeared after taking CM for 10 days. The cause is presumed to be an allergic reaction. His temperature decreased and blood eosinophilia and pulmonary involvements were improved 2 weeks later with the cessation of the drug. However, bilateral ground-glass opacities were temporarily detected on chest $\mathrm{CT}$. Since this CT finding is similar to COVID-19 pneumonia, one must be aware of elevated peripheral blood eosinophilia when using CM for COVID19 treatment.

In an experiment on a mouse model, CM was effective in protecting the mice against death, following a lethal SARS$\mathrm{CoV}$ infection, with a survival rate of $60 \%$ [2]. In this study, the weights of mice were not described, but the average weight was estimated to be approximately $20 \mathrm{~g}$ considering the fact that 6 to 8 -week-old female BALB/c mice were used. Assuming the weights of a mouse and an adult human to be $20 \mathrm{~g}$ and $60 \mathrm{~kg}$, respectively, the equivalent $\mathrm{CM}$ dose for humans would be approximately $2.14 \mathrm{mg} / \mathrm{kg}$. CM has a plasma half-life of $100 \mathrm{~min}$ and is almost completely eliminated in $4-5 \mathrm{~h}$. Thus, taking $600 \mathrm{mg}$ ( $200 \mathrm{mg}$, three times) of CM daily is expected to reduce the SARS-CoV-2 infection. The biggest advantage of using $\mathrm{CM}$ for the treatment of COVID-19 is its low cost (one $100 \mathrm{mg}$ tablet is priced as low as USD 0.10-0.40). This pragmatic treatment has the potential to save the lives of many people, including those belonging to the low-income groups. However, to date, there are no clinical data on the use of the drug in blocking or at least reducing viral spread and pathogenesis of CoVs; therefore, human clinical trials are expected.

Acknowledgements None 
Author contributions UY: contributed to the writing of the manuscript, creation of theory, reference collection.

\section{Compliance with ethical standards}

Conflict of interest The authors declare that they have no conflict of interest.

Statement of human and animal rights This article does not contain any study with human and animals performed by any of the authors.

Informed consent Not applicable.

\section{References}

1. Rabaan AA (2017) Middle East respiratory syndrome coronavirus: five years later. Expert Rev Respir Med 11:901-912
2. Zhou Y, Vedantham P, Lu K et al (2015) Protease inhibitors targeting coronavirus and filovirus entry. Antiviral Res 116:76-84

3. Hoffmann M, Kleine-Weber H, Schroeder S et al (2020) SARSCoV-2 cell entry depends on ACE2 and TMPRSS2 and is blocked by a clinically proven protease inhibitor. Cell 181:1-10

4. Sato T, Uchino J, Matsuno S et al (1992) A dose-finding study of FOY-305 in postoperative reflux esophagitis: a double-blind comparative study. J Clin Therap Med 8:1877-1891 (in Japanese with English abstruct)

5. Ota S, Hara Y, Kanoh S et al (2016) Acute eosinophilic pneumonia caused by camostat mesilate: the first case report. Respir Med Case Rep 19:21-23

Publisher's Note Springer Nature remains neutral with regard to jurisdictional claims in published maps and institutional affiliations. 